RESEARCH REPORT

\title{
Places, people, and their physical and mental functional health
}

\author{
N W J Wainwright, P G Surtees
}

J Epidemiol Community Health 2003;58:333-339. doi: 10.1136/jech.2003.012518

See end of article for authors' affiliations .....................

Correspondence to: Dr N W J Wainwright, Strangeways Research Laboratory, Worts

Causeway, Cambridge CBI 8RN, UK:

nick.wainwright@

srl.cam.ac.uk

Accepted for publication 9 September 2003
A ssociations between individual level measures of socioeconomic status and health are well established. ${ }^{1}$ A focus on area level measures of social context has shown that they can also have an impact on individual health ${ }^{2-4}$ and capture information not available at the individual level ${ }^{5}$ such as community socioeconomic status, availability and access to services, shared culture, and physical features of the local environment such as pollution. ${ }^{46}$ While variation in health at the area level could be attributable to social context, it can also reflect a clustering of similar individuals within areas; for example by age, sex, or social class (composition). Therefore, investigation of the impact of social context on health should include thorough adjustment for the effects of individual level factors. ${ }^{2}{ }^{3}$ Joint models for area and individual level effects can be analysed through standard regression methods by constructing covariates to represent both individual and area level characteristics. However, multilevel (or hierarchical) models are now recommended as a more appropriate method of analysis as residual variation can be taken into account (and quantified) at both the individual and area levels, allowing the effects of context to be easily separated from the effects of composition. ${ }^{2}{ }^{7-9}$

Contextual effects (independent of age, sex, and individual level measures of socioeconomic position) have been demonstrated for health behaviours (including smoking, diet, and physical exercise ${ }^{810-14}$ ) and for a range of physical health outcomes (including incident coronary heart disease, long term illness, mortality, and self reported health ${ }^{815-18}$ ). However, the extent of area level relative to individual level variation is usually modest, ${ }^{23}$ and other studies have produced negative results for similar end points. ${ }^{12}{ }^{19}$ Area based measures of deprivation account for some (but not all) of this area level variation in individual health outcomes. ${ }^{15} 20$

Few studies have investigated the impact of social context on mental health outcomes and these have provided mixed results. ${ }^{821}$ Positive findings reported in relation to depression, schizophrenia, and substance misuse, ${ }^{21-24}$ are in contrast with negative findings reported for depression and for General Health Questionnaire defined psychiatric morbidity. ${ }^{235-27}$
Strategies to improve the quality of life and functional ability of populations are important public health objectives ${ }^{28} 29$ and neighbourhood factors have been shown to be associated with poor physical functioning. ${ }^{30}{ }^{31}$ The Short Form 36 (SF36) provides a validated generic measure of subjective health status derived from the US Medical Outcomes Study. ${ }^{32}$ Few studies have investigated contextual effects in relation to SF36 functional health. ${ }^{34-36}$

A large population based cohort study (the European Prospective Investigation into Cancer and Nutrition in Norfolk, UK (EPIC-Norfolk) ${ }^{13}{ }^{37}$ ) now provides an opportunity to examine contextual effects, through multilevel analysis, for physical and mental functional health as represented by SF-36 summary scores. We specifically ask whether there is area level variation in physical and mental functional health that persists after controlling for important individual level socioeconomic factors, and investigate the extent of any area level as compared with individual level variation.

\section{METHODS}

During 1993-97, EPIC-Norfolk, a large population based cohort study designed to advance understanding of nutritional and other determinants of chronic disease development, recruited participants by post through general practice age-sex registers in Norfolk, England. ${ }^{37}$ In comparison with the general resident population of England, the EPIC-Norfolk cohort is representative in terms of anthropometric variables, blood pressure, and serum lipids, but has fewer current smokers. ${ }^{37}$ During 1996-2000 an assessment of social and psychological circumstances (based upon the Health and Life Experiences Questionnaire (HLEQ) ${ }^{38}$ ) was completed by a total of 20921 participants, representing a response rate of $73.2 \%$ of the total eligible EPIC sample. ${ }^{39}$

Abbreviations: PCS, physical component summary; MCS, mental component summary 


\section{Dependent variables}

The HLEQ included the anglicised Short Form 36 (SF-36). Eight multi-item independent health dimensions (subscales) are represented in the SF-36, namely: physical functioning, social functioning, role limitations because of physical problems, role limitations because of emotional problems, mental health, energy/vitality, pain, and general health perception. Two higher order summary scores representing overall physical and mental health functioning (the physical component summary (PCS), and mental component summary (MCS)), were derived according to algorithms specified by the original developers (that were based on a factor analysis that captured over $80 \%$ of the variance in the eight subscales). ${ }^{40}{ }^{41}$ Subscale scores were based on available data where at least half of the items were entered. Factor score coefficients used to derive the component scores were based upon a US as opposed to a UK population (that produce similar results) on the basis of uniformity for cross national comparisons. ${ }^{42}$ PCS and MCS scores are standardised so that the US population has mean 50 and standard deviation (SD) $10{ }^{41} \mathrm{~A}$ higher score on both summary scales represents better functional health.

\section{Individual level measures}

As part of the HLEQ assessment, details of demographic factors and of either current or prior main work were obtained, enabling standard social class allocation according to computer assisted standard occupational coding. ${ }^{43}$ Current employment status was coded as those working (full time or part time) and not working (either unemployed or economically inactive), as defined by the Office of National Statistics. ${ }^{44}$ Social class was coded as I (professionals), II (managerial and technical occupations), III non-manual and III manual (skilled workers), IV (partly skilled workers), and V (unskilled manual workers). For both men and women, social class was coded based on the male partner's current or prior occupation (or the female partner's occupation where this was unavailable). If data were not available for either partner social class could not be allocated, see Shohaimi et al ${ }^{13}$ for further details. Educational attainment was coded in four categories (those with no formal qualifications, those with formal qualifications usually associated with a school age of 16 years, those with formal qualifications (or vocational equivalent) usually associated with a school age of around 18 years, and those with degree level qualifications). These factors, along with marital status, age, and sex were included as individual level confounding variables.

\section{Area level measures}

Participants in the EPIC-Norfolk study were recruited from a defined geographical area within East Anglia (UK), centred on the city of Norwich and the surrounding small towns and rural areas, which has little outward migration in the study age group. ${ }^{37}$ Area of residence was defined according to the UK electoral register (electoral wards). In year 2000, an overall index of multiple deprivation commissioned by the (then) Department of the Environment, Transport and the Regions, was created for the 8414 electoral wards in England, derived from 32 variables in six domains (income, employment, health deprivation and disability, education skills and training, housing, and geographical access to services).$^{45} \mathrm{~A}$ higher deprivation score represents a more deprived neighbourhood. These data were linked at the electoral ward level to individual level data gathered through the EPIC-Norfolk HLEQ instrument.

\section{Statistical analysis}

Variations in PCS and MCS scores are presented for all individual and area level covariates, adjusted for age (in five year bands) and sex (including age-sex interactions), as $\beta$ coefficients (standard errors) obtained from linear regression models. Area level variation in PCS and MCS scores was assessed through a series of random intercept gaussian multilevel models ${ }^{46}$ with individual at level one and electoral ward at level two. The proportion of variance explained at the area level (equivalent to the intra-class correlation (ICC) for random intercept multilevel models), represents the degree of correlation between the health of people within the same area (electoral ward). We present the percentage of residual variation at the area level $(100 \times \mathrm{ICC})$, unadjusted then adjusted for individual level characteristics, and after additional adjustment for area deprivation. As it was not possible to allocate social class for a sizeable subgroup of participants (see table 1) this subgroup was included in the adjusted analyses as an extra category. Tests of significance of area level variance were obtained from likelihood ratio tests. Analysis was performed in SPlus ${ }^{47}$ and MLwiN. ${ }^{48}$

\section{RESULTS}

Of the HLEQ sample, PCS and MCS scores and linked data at the electoral ward level were available for 18399 participants ( $87.9 \%$ of the sample), aged 41 to 80 years, including 8109 men and 10290 women. Mean scores (standard deviations) for the PCS were 47.8 (9.9) and 47.1 (10.4) for men and women, respectively, and for the MCS were 53.0 (9.0) and 51.6 (9.7). Table 1 shows the sociodemographic composition of the study sample. In this sample, individual SF-36 subscale items had been imputed in the calculation of PCS and MCS summary scores for 2,152 (11.7\% of) participants (involving imputation of only one of 35 items for 1475 and more than three items for just 163 participants).

Study participants were resident in 162 electoral wards with a mean of 114 participants per ward (median 77, range 1 to 780 ). Multiple deprivation scores in the range 5.2 to 58.8 place these 162 wards as ranked between the 7991st and 288th most deprived of the 8414 wards in England, a coverage of $91.5 \%$ of the population distribution of deprivation scores. Of the study participants, $90 \%$ were resident in wards with multiple deprivation scores in the range 7.4 to 37.2, corresponding to ward level ranks of 7307 and 1321 (and a coverage of $71.1 \%$ of the population distribution). The proportion of participants in the non-manual social classes was higher (82.0\% versus $58.2 \%$ ) for those who were resident in the least as compared with most deprived wards, respectively (bottom and top deciles of deprivation scores). Tables 2 and 3 reveal strong age-sex adjusted associations between all individual and area level factors considered and PCS and MCS scores (except for educational attainment and MCS score). Participants who were resident in the more deprived wards reported worse functional health. This association was consistent across the six domain scores of deprivation (except for access to services and PCS score, data not shown). The pattern of associations was generally consistent by sex with the magnitude of associations tending to be greater for men than for women.

Table 4 shows results from multilevel models of PCS and MCS score. Unadjusted for any covariates, significant area level variation was observed for both PCS and MCS scores. Area variation represented $1.1 \%$ of the total variation in PCS scores and was consistent for men $(1.2 \%, \mathrm{p}<0.001)$ as well as for women ( $1.0 \%, \mathrm{p}<0.001)$. Area variation was more modest for MCS, representing only $0.5 \%$ of total variation and was greater for men $(0.9 \%, \mathrm{p}<0.001)$ than for women $(0.4 \%$, $\mathrm{p}=0.007)$. The percentage variation at the area level in PCS and MCS scores was unchanged after excluding those participants for whom SF-36 scale items had been imputed (remaining sample size, $\mathrm{n}=16$ 247). 
Table 1 Sociodemographic composition of the study sample $(n=18399)$

\begin{tabular}{|c|c|c|c|c|c|c|}
\hline & \multicolumn{2}{|l|}{ Men } & \multicolumn{2}{|l|}{ Women } & \multicolumn{2}{|l|}{ All } \\
\hline & Number & (\%) & Number & (\%) & Number & $(\%)$ \\
\hline \multicolumn{7}{|l|}{ Social class } \\
\hline 1 & 719 & (8.9) & 196 & (1.9) & 915 & $(5.0)$ \\
\hline$\|$ & 3163 & $(39.0)$ & 3119 & $(30.3)$ & 6282 & (34.1) \\
\hline IIIn & 747 & (9.2) & 3739 & (36.3) & 4486 & (24.4) \\
\hline IIIm & 1886 & (23.3) & 627 & (6.1) & 2513 & (13.7) \\
\hline IV & 570 & $(7.0)$ & 1033 & (10.0) & 1603 & $(8.7)^{\circ}$ \\
\hline $\mathrm{V}$ & 98 & $(1.2)$ & 377 & (3.7) & 475 & (2.6) \\
\hline Not allocated & 926 & (11.4) & 1199 & (11.7) & 2125 & (11.5) \\
\hline \multicolumn{7}{|l|}{ Marital status } \\
\hline Married/living as married & 7078 & (87.3) & 7662 & (74.5) & 14740 & (80.1) \\
\hline Never married & 310 & (3.8) & 434 & $(4.2)$ & 744 & $(4.0)$ \\
\hline Widowed & 299 & (3.7) & 1350 & (13.1) & 1649 & (9.0) \\
\hline Divorced/separated & 404 & $(5.0)$ & 832 & $(8.1)^{\circ}$ & 1236 & (6.7) \\
\hline \multicolumn{7}{|l|}{ Employment status } \\
\hline Working & 3840 & (47.4) & 4045 & (39.3) & 7885 & $(42.9)$ \\
\hline Not working & 4240 & (52.3) & 6177 & (60.0) & 10417 & $(56.6)$ \\
\hline \multicolumn{7}{|l|}{ Educational attainment } \\
\hline No qualifications & 2376 & (29.3) & 4697 & $(45.6)$ & 7073 & (38.4) \\
\hline To age 16 & 713 & (8.8) & 1724 & (16.8) & 2437 & (13.2) \\
\hline To age 18 & 3758 & (46.3) & 2673 & (26.0) & 6431 & (35.0) \\
\hline Degree level & 1260 & (15.5) & 1190 & (11.6) & 2450 & (13.3) \\
\hline
\end{tabular}

After adjustment for all individual level factors, area level variation in PCS score remained significant but was reduced to $0.6 \%$ of the total residual variation $(0.8 \%, \mathrm{p}<0.001$, for men and $0.5 \%, \mathrm{p}<0.001$, for women). Area deprivation was associated with PCS score, independent of the individual level factors, and accounted for about half of the remaining area level variation. The magnitude of effect for deprivation was smaller than for the most important individual level factors (employment status and social class), as was the magnitude of the area level residuals (from model B: range -1.3 to 1.4 with $90 \%$ in the range -0.5 to 0.4 ). After adjustment for individual level factors, only a small amount of variation in MCS scores remained at the area level $(0.2 \%$ of the total, $p=0.05)$, and was apparent for men $(0.5 \%, p=$ $0.02)$ but not for women $(0.1 \%, p=0.3)$. Area deprivation was associated with MCS score, independent of the individual level factors, but only accounted for $25 \%$ of the remaining area level variation in men. The magnitude of effect for deprivation and the magnitude of the area level residuals (from model B: range -0.5 to 0.4 with $90 \%$ in the range -0.2 to 0.2 ) were again smaller than for the most important individual level factors (marital status and social class).

A final analysis investigated any interaction between social class (as a binary variable; non-manual (I, II, and IIIn) versus

Table 2 Age-sex adjusted associations between individual and area level sociodemographic characteristics and SF-36 physical component summary (PCS) scores ( $\beta$ coefficients (standard errors))

\begin{tabular}{|c|c|c|c|c|c|c|}
\hline & \multicolumn{2}{|l|}{ Men } & \multicolumn{2}{|c|}{ Women } & \multicolumn{2}{|l|}{ All } \\
\hline & $\beta \dagger$ & (SE) & $\bar{\beta}$ & (SE) & $\beta$ & (SE) \\
\hline \multicolumn{7}{|l|}{ Age } \\
\hline $41-54$ & - & - & - & - & - & - \\
\hline $55-64$ & -2.8 & $(0.3)$ & -2.2 & $(0.2)$ & -2.5 & $(0.2)$ \\
\hline $65-80$ & -6.6 & $(0.3)^{\star \star \star}$ & -6.5 & $(0.2)^{\star \star \star}$ & -6.5 & $(0.2)^{\star \star \star}$ \\
\hline \multicolumn{7}{|l|}{ Social class } \\
\hline 1 & - & - & - & - & - & - \\
\hline II & -0.9 & $(0.4)$ & 0.2 & $(0.7)$ & -0.8 & (0.3) \\
\hline IIIn & -1.7 & $(0.5)$ & 0.3 & (0.7) & -1.0 & $(0.4)$ \\
\hline $\mathrm{IIIm}$ & -2.8 & $(0.4)$ & -1.3 & $(0.8)$ & -2.5 & $(0.4)$ \\
\hline IV & -3.4 & $(0.5)$ & -1.0 & $(0.8)$ & -2.5 & $(0.4)$ \\
\hline $\mathrm{V}$ & -5.4 & $(1.0)^{\star \star \star}$ & -2.0 & $(0.9)^{\star * *}$ & -3.6 & $(0.6)^{\star * *}$ \\
\hline \multicolumn{7}{|l|}{ Marital status } \\
\hline Married/living as married & - & - & - & - & - & - \\
\hline Never married & -0.9 & $(0.6)$ & -0.4 & $(0.5)$ & -0.6 & $(0.4)$ \\
\hline Widowed & 0.1 & $(0.6)$ & 0.0 & $(0.3)$ & 0.0 & (0.3) \\
\hline Divorced/separated & 0.0 & $(0.5)$ & -1.4 & $(0.4)^{* *}$ & -0.9 & $(0.3)^{\star *}$ \\
\hline \multicolumn{7}{|l|}{ Employment status } \\
\hline Working & - & - & - & - & - & - \\
\hline Not working & -5.4 & $(0.3)^{* * *}$ & -3.7 & $(0.3)^{\star \star *}$ & -4.4 & $(0.2)^{\star * *}$ \\
\hline \multicolumn{7}{|l|}{ Educational attainment } \\
\hline No qualifications & - & - & - & - & - & - \\
\hline To age 16 & 2.1 & $(0.4)$ & 0.9 & (0.3) & 1.3 & $(0.2)$ \\
\hline To age 18 & 1.2 & $(0.3)$ & 0.8 & $(0.2)$ & 0.9 & $(0.2)$ \\
\hline Degree level & 2.7 & $(0.3)^{* * *}$ & 1.4 & $(0.3)^{* \star *}$ & 2.0 & $(0.2)^{\star * *}$ \\
\hline \multicolumn{7}{|l|}{ Multiple deprivation } \\
\hline per SD increase & -0.8 & $(0.1)^{\star \star \star}$ & -0.5 & $(0.1)^{\star \star \star}$ & -0.6 & $(0.1)^{\star \star *}$ \\
\hline
\end{tabular}


Table 3 Age-sex adjusted associations between individual and area level sociodemographic characteristics and SF-36 mental component summary (MCS) scores ( $\beta$ coefficients (standard errors))

\begin{tabular}{|c|c|c|c|c|c|c|}
\hline & \multicolumn{2}{|l|}{ Men } & \multicolumn{2}{|c|}{ Women } & \multicolumn{2}{|l|}{ All } \\
\hline & $\beta \dagger$ & (SE) & $\beta$ & (SE) & $\beta$ & (SE) \\
\hline \multicolumn{7}{|l|}{ Age } \\
\hline $41-54$ & - & - & - & - & - & - \\
\hline $55-64$ & 1.9 & $(0.3)$ & 2.6 & $(0.2)$ & 2.3 & $(0.2)$ \\
\hline $65-80$ & 3.6 & $(0.2)^{\star \star \star}$ & 3.8 & $(0.2)^{\star \star *}$ & 3.7 & $(0.2)^{\star * *}$ \\
\hline \multicolumn{7}{|l|}{ Social class } \\
\hline I & - & - & - & - & - & - \\
\hline II & -0.3 & $(0.4)$ & -0.9 & $(0.7)$ & -0.4 & (0.3) \\
\hline IIIn & -0.7 & $(0.5)$ & -1.1 & $(0.7)$ & -0.7 & $(0.4)$ \\
\hline $\mathrm{IIIm}$ & -0.6 & $(0.4)$ & -0.9 & $(0.8)$ & -0.6 & $(0.4)$ \\
\hline IV & -1.2 & $(0.5)$ & -1.8 & $(0.7)$ & -1.4 & $(0.4)$ \\
\hline V & -3.5 & $(1.0)^{* *}$ & -1.9 & $(0.8)^{*}$ & -2.0 & $(0.5)^{\star \star \star *}$ \\
\hline \multicolumn{7}{|l|}{ Marital status } \\
\hline Married/living as married & - & - & - & - & - & - \\
\hline Never married & -1.9 & $(0.5)$ & -0.8 & $(0.5)$ & -1.3 & (0.3) \\
\hline Widowed & -1.6 & $(0.5)$ & -1.4 & (0.3) & -1.5 & $(0.3)$ \\
\hline Divorced/separated & -3.4 & $(0.5)^{\star \star *}$ & -3.0 & $(0.3)^{\star * *}$ & -3.2 & $(0.3)^{\star \star *}$ \\
\hline \multicolumn{7}{|l|}{ Employment status } \\
\hline Working & - & - & - & - & - & - \\
\hline Not working & -1.6 & $(0.3)^{\star \star \star}$ & -0.7 & $(0.3)^{* \star}$ & -1.1 & $(0.2)^{\star * *}$ \\
\hline \multicolumn{7}{|l|}{ Educational attainment } \\
\hline No qualifications & - & - & - & - & - & - \\
\hline To age 16 & 0.5 & $(0.4)$ & 0.4 & (0.3) & 0.4 & $(0.2)$ \\
\hline To age 18 & 0.3 & $(0.2)$ & 0.2 & $(0.2)$ & 0.3 & $(0.2)$ \\
\hline Degree level & 0.2 & $(0.3)$ & 0.8 & (0.3) & 0.5 & $(0.2)$ \\
\hline \multicolumn{7}{|l|}{ Multiple deprivation } \\
\hline per SD increase & -0.5 & $(0.1)^{\star \star *}$ & -0.5 & $(0.1)^{\star \star \star}$ & -0.5 & $(0.1)^{\star * *}$ \\
\hline
\end{tabular}

Table 4 Individual and area level variation in SF-36 physical component summary (PCS) and mental component summary (MCS) scores (parameter estimates (standard errors)); A: unadjusted; B: adjusted for individual level characteristics (age, sex, social class, marital status, employment status, and educational attainment, all as categorical variables) and; $C$ : with additional adjustment for area deprivation (continuous)

\begin{tabular}{|c|c|c|c|c|c|c|c|c|c|c|c|}
\hline & \multicolumn{5}{|l|}{ PCS } & \multicolumn{6}{|l|}{ MCS } \\
\hline & A & B & & $\mathrm{C}$ & & A & & B & & $\mathrm{C}$ & \\
\hline \multirow{2}{*}{$\begin{array}{l}\text { Fixed effects } \\
\text { Social class }\end{array}$} & & $\beta \dagger$ & (SE) & $\beta$ & (SE) & & & $\beta$ & (SE) & $\beta$ & (SE) \\
\hline & & & & & & & & & & & \\
\hline \multicolumn{2}{|l|}{ I } & - & - & - & - & & & - & - & - & - \\
\hline \multicolumn{2}{|l|}{ ॥ } & -0.2 & $(0.4)$ & -0.2 & $(0.4)$ & & & -0.4 & (0.3) & -0.3 & $(0.3)$ \\
\hline \multicolumn{2}{|l|}{ IIIn } & 0.0 & $(0.4)$ & 0.0 & $(0.4)$ & & & -0.7 & $(0.4)$ & -0.7 & $(0.3)$ \\
\hline \multicolumn{2}{|l|}{ IIIm } & -1.4 & $(0.4)$ & -1.4 & $(0.4)$ & & & -0.5 & $(0.4)$ & -0.5 & $(0.4)$ \\
\hline \multicolumn{2}{|l|}{ IV } & -1.2 & $(0.4)$ & -1.2 & (0.4) & & & -1.2 & $(0.4)$ & -1.2 & $(0.4)$ \\
\hline \multirow{2}{*}{\multicolumn{2}{|c|}{$\begin{array}{l}\text { V } \\
\text { Marital status }\end{array}$}} & -2.1 & $(0.6)$ & -2.1 & $(0.6)$ & & & -1.8 & (0.5) & -1.7 & $(0.5)$ \\
\hline & \\
\hline & - & - & - & - & & & - & - & - & - \\
\hline \multicolumn{2}{|l|}{ Never married } & -0.2 & $(0.4)$ & -0.1 & $(0.4)$ & & & -1.2 & $(0.4)$ & -1.2 & $(0.4)$ \\
\hline \multicolumn{2}{|l|}{ Widowed } & 0.1 & (0.3) & 0.1 & (0.3) & & & -1.4 & (0.3) & -1.4 & $(0.3)$ \\
\hline \multicolumn{2}{|l|}{ Divorced/separated } & -0.8 & $(0.3)$ & -0.7 & $(0.3)$ & & & -3.1 & (0.3) & -3.0 & $(0.3)$ \\
\hline \multicolumn{12}{|l|}{ Employment status } \\
\hline \multicolumn{2}{|l|}{ Working } & - & - & - & - & & & - & - & - & - \\
\hline \multirow{2}{*}{\multicolumn{2}{|c|}{$\begin{array}{l}\text { Not working } \\
\text { Educational attainment }\end{array}$}} & -4.3 & $(0.2)$ & -4.3 & $(0.2)$ & & & -1.0 & $(0.2)$ & -0.9 & $(0.2)$ \\
\hline & & & & & & & & & & & \\
\hline \multirow{2}{*}{\multicolumn{2}{|c|}{ No qualifications }} & & & & & & & & & & \\
\hline \multirow{2}{*}{\multicolumn{2}{|c|}{$\begin{array}{l}\text { To age } 16 \\
\text { To age } 18\end{array}$}} & 0.9 & $(0.2)$ & 0.8 & (0.2) & & & & & & \\
\hline & & 0.5 & $(0.2)$ & 0.5 & $(0.2)$ & & & & & & \\
\hline \multirow{2}{*}{\multicolumn{2}{|c|}{$\begin{array}{l}\text { Degree level } \\
\text { Multiple deprivation }\end{array}$}} & 1.1 & $(0.3)$ & 1.1 & (0.3) & & & & & & \\
\hline & & & & & & & & & & & \\
\hline \multicolumn{2}{|l|}{ per SD increase } & & & -0.5 & $(0.1)$ & & & & & -0.3 & $(0.1)$ \\
\hline Random effects & (SE) & $\sigma^{2}$ & (SE) & $\sigma^{2}$ & (SE) & $\sigma^{2}$ & (SE) & $\sigma^{2}$ & (SE) & $\sigma^{2}$ & (SE) \\
\hline Individual variation & 102.9 (1.08) & 91.2 & $(0.96)$ & 91.2 & $(0.96)$ & 88.8 & (0.93) & 84.7 & $(0.89)$ & 84.7 & $(0.89)$ \\
\hline Area variation & $1.10(0.25)^{\star \star \star}$ & 0.53 & $(0.16)^{\star * *}$ & 0.30 & $(0.12)^{\star \star \star}$ & 0.44 & $(0.14)^{\star \star \star}$ & 0.15 & $(0.09)^{*}$ & 0.05 & $(0.07)$ \\
\hline$\%$ Area variation $\ddagger$ & 1.1 & 0.6 & & 0.3 & & 0.5 & & 0.2 & & 0.1 & \\
\hline
\end{tabular}




\section{Key points}

- Contextual effects have been demonstrated for a range of physical health outcomes but results from the few studies of mental health outcomes have been mixed.

- This study has provided evidence for area level variation in physical functional health, independent of individual level socioeconomic factors.

- The combination of low social class and living in a deprived area resulted in especially low levels of reported physical functional health.

- Evidence for an association for mental functional health was weak.

- In agreement with previous studies, the magnitude of the association observed at the area level was modest.

manual (IIIm, IV and V)) and multiple deprivation, adjusted for all other individual level covariates. Some evidence for an interaction was found for PCS $(p=0.05)$ but not for MCS score $(p=0.13)$. Figure 1 shows adjusted mean PCS scores by social class across the range of multiple deprivation scores and reveals that the disparity in functional health between social classes widens with increasing area deprivation.

\section{DISCUSSION}

This study has provided evidence for an association between area of residence and self reported physical functional health. Those participants who were resident in the more deprived neighbourhoods reported worse physical functional health than residents of the less deprived neighbourhoods. However, the extent of variation at the area level, after controlling for important individual level socioeconomic factors, was modest in comparison to variation at the individual level. About half of this association could be accounted for by an index of multiple deprivation that combined area level domain scores of income, employment, health deprivation and disability, education skills and training, housing, and geographical access to services. There was some evidence of an interaction effect between social class and area deprivation such that the combination of low social class and living in a deprived area

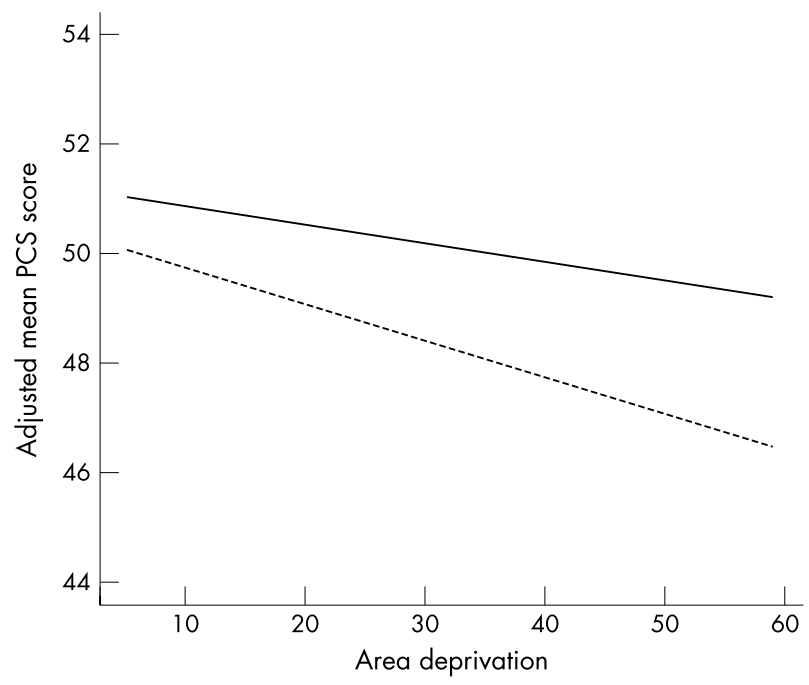

Figure 1 Interaction between social class and area deprivation; mean SF-36 physical component summary (PCS) score (adjusted for individual level covariates) by increasing area deprivation and by social class (nonmanual; I, II and IIIn-solid line: and manual; IIIm, IV, V-dashed line). resulted in especially low levels of reported physical functional health. While area deprivation was associated with poor mental functional health, residual variation at the area level, after adjusting for individual level socioeconomic factors, was modest and was observed for men but not for women.

The results from this study were obtained from a multilevel analysis of individual and area level socioeconomic factors. Multilevel models have a number of advantages over more traditional (single level) regression approaches.. ${ }^{2} 79$ However, the results obtained are necessarily limited by the quality of the data to which they are applied, ${ }^{3}$ and the power to detect variability at the area level depends both on the number of areas and on the average number of people within each area. $^{23}$ Although, there was wide variation in the number of people across the 162 electoral wards, the size of this study cohort is a major strength. However, evidence for residual variation in mental functional health at the area level was weak and inconsistent despite a significant association for an area level covariate (multiple deprivation). While this indicates that power to detect variation at the area level remains an issue, given the large sample the effect size for the association between area and mental functional health is arguably too small to be of practical importance in this study.

A number of other important limitations warrant further comment. Firstly, the data used for this study were cross sectional and we are therefore unable to comment on the direction of causation. While area of residence could adversely affect physical functional health, a person's functional health might also influence (or limit) their choice of area of residence. Secondly, the specification of areas is based on administrative boundaries (driven by practical considerations) and therefore has no explicit theoretical justification. This may have compromised the capacity of these data to detect variation at the area level. Thirdly, while we have included adjustment for individual level social class, marital status, employment status, and educational attainment, the presence of significant variation at the area level could be attributable to the omission of other important individual level covariates. However, as the distinction between individual and area level factors is not always clear (for example, individual social class can be influenced by the availability of work or other local area economic factors), ${ }^{49} 50$ it also possible that we have underestimated the impact of area through overadjusting for individual level socioeconomic status. No adjustments were made in this study for individual level behavioural measures (for example, smoking and physical activity) or for cardiovascular risk factors (for example, blood pressure and cholesterol). As previous studies have provided evidence of contextual effects for these measures, ${ }^{8} 101451$ they were considered as potential mediators and therefore not included as confounders. ${ }^{25}$ Fourthly, the age range (41-80), social class distribution (predominantly non-manual), and type of geographical area studied may limit the generalisability of results. However, deprivation scores from the 162 electoral wards in this study did cover $90 \%$ of the range of deprivation scores for all 8414 wards in England, although it remains possible that results will not be generalisable for residents of areas that are either extremely deprived or extremely affluent.

Few studies have investigated contextual effects in relation to SF-36 functional status. A recent UK study of 2190 people, aged 18 to 75 and resident in 15 neighbourhoods (electoral wards $)^{35}$ reported appreciable differences between areas for seven of the eight SF-36 subscale scores and concluded that the relation between material deprivation and functional health was strong enough to be of practical importance. However, area level results from this study were based on an 
aggregate analysis and did not include simultaneous adjustment for individual level socioeconomic factors. A study of Canadian adults reported a multilevel analysis of SF-36 subscale and summary scores and concluded that variation between nine sites was not clinically important. ${ }^{36}$ Our findings are broadly in line with those from a recent large scale study of US veterans in a primary care setting. ${ }^{34}$ Based on a single level analysis of 17234 people across seven geographical sites, the study reported substantial variation between sites for both the SF-36 physical and mental component summary scores. However, after adjustment for individual level factors, geographical site accounted for only a small percentage of explained variation in physical functional health and an even smaller percentage of variation in mental functional health.

The joint investigation of social context and individual level variables can provide a more complete understanding of the determinants of disease $\mathrm{e}^{5}$ as well as a basis for planning improvements in public health. ${ }^{6}$ Most previous studies have shown some evidence for the impact of social context on physical health outcomes and behaviours, whereas only a few studies have investigated the impact of social context on mental health outcomes, and with mixed results. ${ }^{8}$ This study has provided evidence for an association between social context and physical functional health, independent of individual level socioeconomic factors, whereas evidence for an association between social context and mental functional health was weak. In agreement with previous studies, the magnitude of the association observed at the area level was modest when compared with the magnitude of associations at the individual level. At a public health policy level these results imply that while improvements in health might be achieved at both the individual and area levels, greater rewards might be gained from interventions targeted at the person rather than the area.

\section{ACKNOWLEDGEMENTS}

We are grateful to Dr David Spiegelhalter (Medical Research Council Biostatistics Unit, Cambridge, UK) for his helpful comments on an earlier draft of this manuscript.

\section{Authors' affiliations}

N W J Wainwright, P G Surtees, Strangeways Research Laboratory and Department of Public Health and Primary Care, Institute of Public Health, University of Cambridge, UK

Funding: EPIC-Norfolk is supported by programme grants from Cancer Research UK and Medical Research Council with additional support from the Stroke Association, the British Heart Foundation, the Department of Health, the Food Standards Agency and the Wellcome Trust, and the Europe Against Cancer Programme of the Commission of the European Communities.

Conflicts of interest: none declared.

\section{REFERENCES}

1 Marmot M. Inequalities in health. N Engl J Med 2001;345:134-6.

2 Diez Roux AV. Multilevel analysis in public health research. Annu Rev Public Health 2000;21:171-92

3 Duncan C, Jones K, Moon G. Context, composition and heterogeneity: using multilevel models in health research. Soc Sci Med 1998:46:97-117.

4 Yen IH, Syme SL. The social environment and health: a discussion of the epidemiologic literature. Annu Rev Public Health 1999;20:287-308.

5 Diez Roux AV. Bringing context back into epidemiology: variables and fallacies in multilevel analysis. Am J Public Health 1998;881:216-22.

6 Macintyre S, Maciver S, Sooman A. Area, class and health: should we be focusing on places or people? Journal of Social Policy 1993;22:213-34.

7 Greenland S. Principles of multilevel modelling. Int J Epidemiol 2000;29:158-67.

8 Pickett KE, Pearl M. Multilevel analyses of neighbourhood socioeconomic context and health outcomes: a critical review. J Epidemiol Community Health $2001 ; 55: 111-22$

9 Von Korff M, Koepsell T, Curry S, et al. Multi-level analysis in epidemiologic research on health behaviors and outcomes. Am J Epidemiol 1992;135: 1077-82.
10 Duncan C, Jones K, Moon G. Smoking and deprivation: are there neighbourhood effects? Soc Sci Med 1999;48:497-505.

11 Diez Roux AV, Stein Merkin S, Hannan P, et al. Area characteristics, individual-level socioeconomic indicators, and smoking in young adults: The Coronary Artery Disease Risk Development in Young Adults Study. Am J Epidemiol 2003;157:315-26.

12 Ecob R, Macintyre S. Small area variations in health related behaviours; do these depend on the behaviour itself, its measurement, or on personal characteristics? Health Place 2000;6:261-74.

13 Shohaimi S, Luben R, Wareham N, et al. Residential area deprivation predicts smoking habit independently of individual educational level and occupational social class. A cross sectional study in the Norfolk cohort of the European Investigation into Cancer (EPIC-Norfolk). J Epidemiol Community Health 2003:57:270-6.

14 Yen IH, Kaplan GA. Poverty area residence and changes in physical activity level: evidence from the Alameda County Study. Am J Public Health 1998:88:1709-12.

15 Diez Roux AV, Merkin SS, Arnett D, et al. Neighborhood of residence and incidence of coronary heart disease. N Engl J Med 2001;345:99-106.

16 Shouls S, Congdon P, Curtis S. Modelling inequality in reported long term illness in the UK: combining individual and area characteristics. J Epidemiol Community Health 1996:50:366-76.

17 Waitzman NJ, Smith KR. Phantom of the area: poverty-area residence and mortality in the United States. Am J Public Health 1998;88:973-6.

18 Malmstrom M, Sundquist J, Johansson SE. Neighborhood environment and self-reported health status: a multi-level analysis. Am J Public Health 1999;89:1181-6.

19 Sloggett A, Joshi $\mathrm{H}$. Higher mortality in deprived areas: community or personal disadvantage. BMJ 1994;309:1470-4

20 Boyle PJ, Gatrell AC, Duke-Williams O. Do area-level population change, deprivation and variations in deprivation affect individual-level self-reported limiting long-term illness? Soc Sci Med 2001:53:795-9.

21 Silver E, Mulvey EP, Swanson JW. Neighborhood structural characteristics and mental disorder: Faris and Dunham revisited. Soc Sci Med 2002;55: 1457-70

22 Ross CE. Neighborhood disadvantage and adult depression. J Health Soc Behav 2000:41:177-87.

23 Goldsmith HF, Holzer CE, Manderscheid RW. Neighborhood characteristics and mental illness. Eval Program Plann 1998;21:211-25.

24 Van Os J, Driessen G, Gunther N, et al. Neighbourhood variation in incidence of schizophrenia - Evidence for person-environment interaction. Br J Psychiatry 2000;176:243-8.

25 Duncan C, Jones K, Moon G. Psychiatric morbidity: a multi-level approach to regional variations in the UK. J Epidemiol Community Health 1995:49:290-5.

26 Reijneveld SA, Schene AH. Higher prevalence of mental disorders in socioeconomically deprived urban areas in the Netherlands: community or personal disadvantage? J Epidemiol Community Health 1998;52:2-7.

27 Weich S, Holt G, Twigg L, et al. Geographic variation in the prevalence of common mental disorders in Britain: a multilevel investigation. Am J Epidemiol 2003; 157:730-7.

28 Barbotte E, Guillemin F, Chau N. Prevalence of impairments, disabilities, handicaps and quality of life in the general population: a review of recent literature. Bull World Health Organ 2001;79:1047-55.

29 McHorney CA. Health status assessment methods for adults: past accomplishments and future challenges. Annu Rev Public Health 1999;20:309-35.

30 Balfour JL, Kaplan GA. Neighborhood environment and loss of physical function in older adults: Evidence from the Alameda County Study. Am J Epidemiol 2002; 155:507-15.

31 Ross CE, Mirowsky J. Neighborhood disadvantage, disorder, and health. $J$ Health Soc Behav $2001 ; 42: 258-76$.

32 Ware JE, Sherbourne CD. The MOS 36-item Short-Form Health Survey (SF36). I. Conceptual framework and item selection. Med Care 1992;30:473-83.

33 Stewart AL, Greenfield S, Hays RD, et al. Functional status and well-being of patients with chronic conditions - results from the Medical Outcomes Study. JAMA 1989:262:907-13.

34 Au DH, McDonell MB, Martin DC, et al. Regional variations in health status. Med Care 2001;39:879-88.

35 Marsh P, Carlisle R, Avery AJ. How much does self-reported health status, measured by the SF36, vary between electoral wards with different Jarman and Townsend scores? Br J Gen Pract 2000;50:630-4.

36 Hopman WM, Berger C, Joseph L, et al. Is there regional variation in the SF36 scores of Canadian adults? Can J Public Health 2002;93:233-7.

37 Day N, Oakes S, Luben R, et al. EPIC-Norfolk: study design and characteristics of the cohort. Br J Cancer 1999;80(suppl 1):95-103.

38 Surtees PG, Wainwright NWJ, Brayne C. Psychosocial aetiology of chronic disease: a pragmatic approach to the assessment of lifetime affective morbidity in an EPIC component study. J Epidemiol Community Health 2000:54:114-22.

39 Surtees PG, Wainwright NWJ, Khaw KT, et al. Inflammatory dispositions: a population-based study of the association between hostility and peripheral leukocyte counts. Pers Indiv Differ 2003;35:1271-84.

40 Ware JE, Snow KK, Kosinski M et al. SF-36 health survey: manual and interpretation guide. Boston: Nimrod Press, 1993.

41 Ware JE, Kosinski M, Keller S. SF-36 physical and mental health summary scales: a user's manual. Boston: The Health Institute, New England Medical Center, 1994.

42 Jenkinson C. Comparison of UK and US methods for weighting and scoring the SF-36 summary measures. J Public Health Med 1999;21:372-6. 
43 Elias P, Halstead K, Prandy K. CASOC : computer-assisted standard occupational coding. London: HMSO, 1993.

44 Meltzer H, Gill B, Petticrew M, et al. OPCS surveys of psychiatric morbidity in Great Britain. Report 1. The prevalence of psychiatric morbidity among adults living in private households. London: HMSO, 1995.

45 DETR. Indices of Deprivation 2000. London: Department of the Environment, Transport and the Regions (DETR), 2000.

46 Goldstein HG. Multilevel statistical models. London: Arnold, 1995.

47 Chambers JM, Hastie TJ. Statistical models in S. Pacific Grove: Wadsworth and Brooks-Cole, 1992.
48 Rasbash J, Browne W Goldstein $\mathrm{H}$, et al A user's guide to MLwiN, version 2. 1c. London: Institute of Education, 2000.

49 Macintyre S, Ellaway A, Cummins S. Place effects on health: how can we conceptualise, operationalise and measure them? Soc Sci Med 2002;55:125-39.

50 Macintyre S, Ellaway A. Neighborhoods and health: an overview. In: Kawachi I, Berkman LF, eds. Neighborhoods and health. New York: Oxford University Press, 2003.

51 Hart C, Ecob R, Davey Smith G. People, places and coronary heart disease risk factor: a multilevel analysis of the Scottish Heart Health Study archive. Soc Sci Med 1997;45:893-902.

Incidence of cancer among UK Gulf war veterans: cohort study

Gary J Macfarlane, Anne-Marie Biggs, Noreen Maconochie, Matthew Hotopf, Patricia Doyle, Mark Lunt

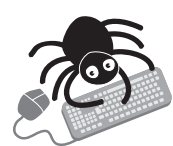

Please visit the Journal of Epidemiology and

Community Health website [www.jech. com] for a link to the full text of this article.
Objectives: To determine whether incidence rates of cancer are higher in UK service personnel who were deployed in the Gulf war than in those not deployed and whether any increased risk of cancer is related to self reported exposures to potentially hazardous material during the period of deployment.

Design: A cohort study with follow up from 1 April 1991 (the end of the Gulf war) to 31 July 2002.

Participants: 51721 Gulf war veterans and 50755 service personnel matched for age, sex, rank, service, and level of fitness who were not deployed in the Gulf (the Era cohort).

Main outcome measures: Incident cancers, identified on the NHS central register.

Results: There were 270 incident cancers among the Gulf cohort and 269 among the Era cohort (incidence rate ratio $0.99,95 \%$ confidence interval 0.83 to 1.17 ). There was no excess in site specific cancers among the Gulf cohort. Adjustment for lifestyle factors (smoking and alcohol consumption) did not alter these results. In the Gulf cohort, risk of cancer was not related to multiple vaccinations or exposure to pesticides or depleted uranium during deployment.

Conclusion: There is no current excess risk of cancer overall nor of site specific cancers in Gulf war veterans. Specific exposures during deployment have not resulted in a subsequent increased risk of cancer. The long latent period for cancer, however, necessitates the continued follow up of these cohorts.

\ $B M J$ 2003;327:1373-1375. 